\title{
Insecticide Transfer Efficiency and Lethal Load in Argentine Ants
}

L.M. Hooper-Bui ${ }^{1,2}$, E.S.C. Kwok ${ }^{3}$, B.A. Buchholz ${ }^{4,5}$, M.K. Rust ${ }^{2}$, , D.A. Eastmond ${ }^{3}$, J.S. Vogel $^{4}$

${ }^{1}$ Department of Environmental Science, Louisiana State University, Baton Rouge, LA 70803

${ }^{2}$ Department of Entomology, University of California, Riverside, CA 92521

${ }^{3}$ Department of Cell Biology and Neuroscience, University of California, Riverside, CA 92521

${ }^{4}$ Center for Accelerator Mass Spectrometry, Lawrence Livermore National Laboratory, Livermore, CA 94551

${ }^{5}$ Department of Environmental Toxicology, University of California, Davis, CA 95616

\begin{abstract}
Trophallaxis between individual worker ants and the toxicant load in dead and live Argentine ants (Linepithema humile) in colonies exposed to fipronil and hydramethylnon experimental baits were examined using accelerator mass spectrometry (AMS). About $50 \%$ of the content of the crop containing trace levels of ${ }^{14} \mathrm{C}$-sucrose, ${ }^{14} \mathrm{C}$-hydramethylnon, and ${ }^{14} \mathrm{C}$-fipronil was shared between single donor and recipient ants. Dead workers and queens contained significantly more hydramethylnon (122.7 and $22.4 \mathrm{amol} / \mu \mathrm{g}$ ant, respectively) than did live workers and queens (96.3 and $10.4 \mathrm{amol} / \mu \mathrm{g}$ ant, respectively). Dead workers had significantly more fipronil (420.3 amol/ $\mu \mathrm{g}$ ant) than did live workers (208.5 amol/ $\mu \mathrm{g}$ ant), but dead and live queens had equal fipronil levels (59.5 and $54.3 \mathrm{amol} / \mu \mathrm{g}$ ant, respectively). The distribution of fipronil differed within the bodies of dead and live queens; the highest amounts of fipronil were recovered in the thorax of dead queens whereas live queens had the highest levels in the head. Resurgence of polygynous ant colonies treated with hydramethylnon baits may be explained by queen survival resulting from sublethal doses due to a slowing of trophallaxis throughout the colony. Bait strategies and dose levels for controlling insect pests need to be based on the specific toxicant properties and trophic strategies for targeting the entire colony.


Key words: Argentine ant, Linepithema humile, trophallaxis, resurgence, hydramethylnon, fipronil, accelerator mass spectrometry, AMS, 


\section{Introduction}

The Argentine ant (Linepithema humile (Mayr)) is an exotic invasive pest species, commonly found in and around homes in coastal California and in Mediterranean climates around the world [1-6]. It replaces native ant species in these environments, presenting a hazard to pollination of native plants, and represents a major threat to native animals through ecosystem degradation [7-9]. As an invading species, a colony can expand the local infested zone by 16 to $30 \mathrm{~m}$ per year in linear directions [2].

Argentine ants are polygynous, having multiple queens in each colony. Queens lay all the eggs and control many of the workers' actions through pheromones [10]. All of the multiple Argentine ant queens in the colony are fertile and actively produce eggs, but one or more are dominant at a given time with the other queens held in "reserve" [11]. Foraging workers (and rarely queens) deliver nutrients to other workers, larvae, or queens by trophallaxis: the regurgitation and feeding the contents of the crop of one ant to another [12]. Queens, larvae, and young workers within the nest receive their primary nutrient intake from stomatodeal trophallaxis with the foragers or other nestmates [13]. The route by which the queens obtain their nutrients is a key factor in controlling ant colonies using baits, since sufficient toxic bait must reach all queens to halt reproduction and to prevent resurgence of a colony [14]. Stringer et al. (1964) [15] found that toxicants must have a delayed toxicity over a wide range of doses, be readily transferred via trophallaxis and not be repellent when incorporated into baits. Cassill and Tschinkel (1996) [16] studied trophallaxis in ant colonies but did not document the effects of a toxicant on this behavior. It is assumed that effective toxic baits do not dramatically alter the flow of food throughout the colony. The detailed distribution of a toxicant within the queens and individuals of a naturally feeding colony can reveal the toxic and sublethal actions 
of different pesticides and provide necessary data for minimizing pesticide use while obtaining the most effective control of these important pests.

Hydramethylnon belongs to the amidinohydrazone class of insecticides that diffuses through the mitochondrial membrane and inhibits the flow of electrons from NADH, preventing metabolism and causing death through inhibition of cellular respiration [17]. Hydramethylnon is considered environmentally sound because it is photolabile with a half-life of 41 min when exposed to sunlight [18]. Fipronil is a phenyl-pyrazole insecticide that blocks GABA-gated chloride channels [19,20]. Fipronil provides lasting action against a variety of insects at very low doses, but it is extremely toxic to honeybees, highly toxic to aquatic organisms and toxic to terrestrial game birds [21]. It is also toxic to fish and mammals [21]. Its primary toxic effect is on the muscular and central nervous systems [21]. Bait preparations as dilute as $0.1 \%$ hydramethylnon or $1 \times 10^{-5 \%}$ fipronil kill Argentine ants [22]. The trophic strategies throughout an ant colony can be masked by the lethal amounts of isotope-labeled toxicant needed in the foraging ants to provide a measurable ${ }^{14} \mathrm{C}$ signal within the layers of colony members. We compared the transfer, toxicity and sublethal effects of these two insecticides on individual ants and on colony-sized groups using AMS detection of ${ }^{14} \mathrm{C}$-labeled forms of these toxicants.

\section{METHODS}

\section{Trophallaxis}

Ants were excavated with surrounding soil from a citrus grove on the campus of University of California, Riverside and placed in large wooden boxes with Teflon and farnesol 
barriers painted along the inside upper $2-3 \mathrm{~cm}$ surface to prevent escape. As the soil dried, the ants moved onto moistened disks made of plaster of Paris ( $9 \mathrm{~cm}$ diam.), affecting colony-wide collection of queens, larvae, pupae, and workers. The ants were transferred from the plaster discs into plaster residences (“condos") in large Petri-dishes (9 cm diam) in which the center was hallowed to allow observation of the ants without disturbance [23]. These colonies were provisioned with $250 \mathrm{mg} / \mathrm{mL}$ sugar water, $0.47 \mathrm{~L}$ jars covered with a fine screen lid allowing ants access but preventing 50 nymphal live German cockroaches, Blattella germanica (L.) from escaping, plastic dishes containing house fly, Musca domestica L. pupae, and water ad libitum. Prior to dosing with labeled compounds, food and water were withdrawn from the subjects for $96 \mathrm{~h}$, approximating the nutritional conditions of foraging Argentine ants in the field [12].

Randomly selected individual workers were removed from inside or outside the condo of fasting ants. Individual ants were pre-weighed to the nearest $\mu \mathrm{g}$ by placing in a gelatin capsule and released into a small Petri dish with sides coated with Teflon to prevent escape. Ants fed to satiation on ${ }^{14} \mathrm{C}$-sucrose (UL) bait contained in pre-weighed $5 \mu \mathrm{L}$ capillary tubes holding $200 \mathrm{mg} / \mathrm{mL}$ sucrose with a specific activity of $558 \mathrm{MBq} / \mathrm{g}(5.16 \mathrm{mCi} / \mathrm{mmol})$ that was then removed after feeding. The amount of bait taken and the additional weight of the ant were determined as described above. Ants that fed on $>0.1 \mathrm{mg}$ of solution were marked with a few specks of fluorescent powder $(<$ than $1 \mu \mathrm{g})$ and designated as donors. Another weighed worker was placed in the Petri dish with the donor ant, and the two remained in the Petri dish until a trophallaxis exchange was complete. Each ant was re-weighed to find the mass transfer of bait solution, and levels of ${ }^{14} \mathrm{C}$-sucrose transfer were determined by scintillation counting. Each ant was placed in a marked $20 \mathrm{ml}$ scintillation vial with $80 \mu \mathrm{l}$ of $15.8 \mathrm{~N}$ nitric acid for $96 \mathrm{~h}$ until the ant was completely dissolved. Cytoscint (ICN Chemicals) scintillation fluid (10 mL) was added 
to each vial and shaken vigorously for $10 \mathrm{~s}$. After the contents of the vials settled for $\sim 1 \mathrm{~h}$, they were placed on the liquid scintillation counter (Beckman Instruments LS 3801) and counted for 1h or until the disintegrations per minute (DPMs) had a sigma value of 2 . The percent transfer was by dividing the amount of ${ }^{14} \mathrm{C}$-sucrose in the recipient by the total ${ }^{14} \mathrm{C}$-sucrose in the donor and recipient and multiplied by 100 .

Next, ${ }^{14} \mathrm{C}$-pyrimidinyl-labeled hydramethylnon and ${ }^{14} \mathrm{C}$-fipronil (Figure 1) in 200 $\mathrm{mg} / \mathrm{mL}$ sucrose preparations were fed at sub-lethal levels to both workers and queens via trophallaxis from bait-fed worker ants as described above for the sucrose controls. Technical grade hydramethylnon and ${ }^{14} \mathrm{C}$-hydramethylnon were provided by The Clorox Service Corporation. The ${ }^{14} \mathrm{C}$-hydramethylnon was diluted to a specific activity of $41.2 \mathrm{kBq} / \mathrm{g}(0.00055$ $\mathrm{mCi} / \mathrm{mmol}$ ) and added with $1.9 \%$ ethanol to produce a $1.0 \mathrm{mg} / \mathrm{mL}$ suspension of hydramethylnon in $200 \mathrm{mg} / \mathrm{mL}$ sucrose. Technical grade fipronil and ${ }^{14} \mathrm{C}$-fipronil were provided by Rhône-Poulenc Ag. Co. The ${ }^{14}$ C-fipronil was diluted to a specific activity of 2.12 $\mathrm{MBq} / \mathrm{g}(0.025 \mathrm{mCi} / \mathrm{mmol})$ to produce a preparation of $0.1 \mu \mathrm{g} / \mathrm{mL}$ of fipronil in $200 \mathrm{mg} / \mathrm{mL}$ sucrose. Both pesticide bait preparations possessed $\mathrm{F}^{14} \mathrm{C} \approx 80$ modern. Positive and negative control levels of ${ }^{14} \mathrm{C}$ were measured in recipients that did not engage the available donor and ants taken randomly from the unexposed condo, respectively. After trophallactic exchange, the levels of ${ }^{14} \mathrm{C}$-hydramethylnon and ${ }^{14} \mathrm{C}$-fipronil in individual donors and recipients were determined by AMS.

\section{Toxicant Load}


Colonies of Argentine ants were established as described above, consisting of 200 workers, $3 \mathrm{~mm}^{2}$ assorted larvae and pupae, and 10-15 queens. Only the cockroaches, house fly pupae, and sucrose solution were removed $96 \mathrm{~h}$ prior to presentation of $0.5 \mathrm{ml}$ of either the ${ }^{14} \mathrm{C}$ hydramethylnon suspension ( 3 replicate colonies) or the ${ }^{14} \mathrm{C}$-fipronil preparation ( 3 replicate colonies) in glass culture tubes. The ants fed freely on the ${ }^{14} \mathrm{C}$-toxicant in $200 \mathrm{mg} / \mathrm{ml}$ sucrose solution for $24 \mathrm{~h}$ before the normal sucrose water and fly pupae were returned to the colony. The colonies were monitored daily and were sampled when about half of the workers and queens in each colony died (3 days). Dead and live workers (10 each) and queens (5 each) were then removed from each colony under these conditions of $50 \%$ lethality to explore the distribution of toxicants within individuals. The queens were large enough $(\sim 3 \mathrm{mg})$ for dissection of the head, thorax and abdomen to find the toxicant load and its location in the body. The workers $(\sim 300 \mu \mathrm{g})$ were only quantified as whole insects.

\section{$A M S$}

All samples were combusted to $\mathrm{CO}_{2}$ and reduced to graphite using Vogel's method [24] at UC Riverside following procedures for biological tracer ${ }^{14} \mathrm{C}$-AMS laboratory hygiene [25]. The graphite samples were loaded into aluminum targets, shipped to Lawrence Livermore National Laboratory and analyzed on the High Voltage Engineering Europa FN-class AMS spectrometer system operating as described previously [26-28].

\section{Statistical software}

Transfer efficiency of sucrose controls and ${ }^{14} \mathrm{C}$-hydramethylnon or ${ }^{14} \mathrm{C}$-fipronil as well as toxicant loads of live and dead workers and portions of dead and live queens were compared using a paired $t$-test (Excel). The body weight and the amount of toxicant each ant contained were compared using regression analysis (Statview 1992).

\section{RESULTS}




\section{Sucrose trophallaxis}

The average transfer efficiency for ${ }^{14} \mathrm{C}$-sucrose measured by LSC was the same $(\mathrm{P}=0.83)(t$ test) for recipients from outside and inside the condo, $49.5 \%+8.2$ and $52.5 \%+11.3$ (mean + SEM), respectively. There were more feeding contacts between outside workers as donors and inside workers as receivers than any other combination. Many of the workers chosen as recipients from outside the condo did not participate in trophallaxis at all. We thereafter used workers from inside the condo as recipients for the determination of pesticide transfer efficiency experiments.

\section{Pesticide Trophallaxis}

The transfer efficiency of $1.0 \mathrm{mg} / \mathrm{mL}$ hydramethylnon in $20 \%$ sucrose bait, was $54.8+$ $3.5 \%$, which was not significantly different from the sucrose controls $(\mathrm{P}=0.89$; Tcrit $=2.23$; $\mathrm{df}$ $=10$ (Statview 1992). The transfer efficiency of $0.1 \mu \mathrm{g} / \mathrm{mL}$ fipronil in $20 \%$ sucrose bait was similar at $51.9+17.7 \%$. The range of hydramethylnon passed from donor to recipient was $46-$ $60 \%$, and the range of fipronil passed was 24 to $75 \%$.

\section{Pesticide Distribution in Colonies}

The toxicant loads of ants exposed to $1 \mathrm{mg} / \mathrm{ml}{ }^{14} \mathrm{C}$-hydramethylnon are shown in Figure 2 as concentrations per microgram of body tissue. The dead workers had higher toxicant concentrations than did live workers, although the differences were not statistically significant $\left(\mathrm{T}_{\text {crit }}=2.20 ; \mathrm{P}=0.85 ; \mathrm{df}=17\right)$. There was no association between the dry weight of dead workers and the amount of toxicant they received $\left(\mathrm{R}^{2}=0.00095 ; \mathrm{P}=0.924\right)$ and a slight dependence between live worker weights and delivered dose $\left(\mathrm{R}^{2}=0.663 ; \mathrm{P}=0.026\right)$. The toxicant concentration in queens was much lower than that of workers as shown in Figure 2 where there is a scale factor of 10 between the two sections. However, live queens received total hydramethylnon doses equal to those of live workers, with dead queens receiving twice 
the total hydramethylnon as live queens. Dead and live queens did not have significantly different amounts of hydramethylnon in the head or thorax, but there were significantly higher levels of hydramethylnon in the abdomens of the dead queens compared to live queens $\left(\mathrm{T}_{\text {crit }}=\right.$ 2.78; $\mathrm{P}=0.038 ; \mathrm{df}=4)$. There was no association between the weight of dead or live queens and the amount of hydramethylnon found in their bodies $\left(\mathrm{R}^{2}=0.209 ; \mathrm{P}=0.135 ; \mathrm{R}^{2}=0.111 ; \mathrm{P}\right.$ $=0.289$; respectively) .

The concentration of fipronil in ants exposed to $0.1 \mu \mathrm{g} / \mathrm{mL}{ }^{14} \mathrm{C}$-fipronil is shown in Figure 3. Live workers had significantly less ${ }^{14} \mathrm{C}$-fipronil than did the dead workers $(\mathrm{df}=16$; $\mathrm{t}=2.26 ; \mathrm{P}=0.04)$, and there was no association between the dry weight of dead and live workers and the amount of toxicant they received. The concentration of ${ }^{14} \mathrm{C}$-fipronil per $\mu \mathrm{g}$ of tissue in queens was lower than that of workers, as seen in Figure 3 where again there is a factor of 10 difference between the scales. Queens weigh much more than workers and received a larger total mass of fipronil than did workers. In addition, the fipronil clearly accumulated in the queens from multiple feedings by workers that were carrying lower masses of fipronil at higher bodily concentrations.

Dead and live queens in this study did not receive different total doses of fipronil, with the distinction in viability reflected in the distribution of the toxicant within the queens. Those queens that were still alive had a high concentration of fipronil in the head while those that were dead had high concentrations of fipronil in the thorax where it could act on the central nervous system and the neuromuscular junctions. Heads of the dead queens had less than half the fipronil as those from live queens, whereas the thoraxes of dead queens contained more than four times the fipronil found in live queens (statistically significant, $\mathrm{df}=9 ; \mathrm{t}$-stat=2.26; $\mathrm{P}=$ 
0.043). There were no significant differences between the levels of fipronil in the abdomens of live or dead Argentine ant queens $(\mathrm{P}=0.69)$, and there was no association between the dry weight of dead or live queens and the amount of fipronil found in their bodies $(\mathrm{df}=1,19 ; \mathrm{F}=1.6$; $\mathrm{P}=0.215 ; \mathrm{df}=1,12 ; \mathrm{F}=0.226 ; \mathrm{P}=0.615 ;$ respectively).

\section{Discussion}

We showed that the presence or action of a delayed acting toxicant such as fipronil did not alter individual trophallactic behavior between individual donors and recipients of ${ }^{14} \mathrm{C}$ fipronil. An earlier study found that there may be temporal polyethism (distinct division of labor) in Argentine ants because workers found inside the nest have a higher survival rate than did workers outside the nest [29]. Workers from inside the nest may be fed directly by outside workers while inside workers distribute the nutrients (and toxicants) within the colony, preferentially choosing trophallaxis with the currently reproducing queens [29].

Solid hydramethylnon baits significantly suppressed the number of workers of southern fire ant, Solenopsis xyloni (McCook) colonies for about 6 months [30]. New entrances to ant colonies appear within $10 \mathrm{~m}$ of the original baited colony between a few days to several months after baiting, and other colonies may reappear within several months at the same site, showing that not all queens were killed [30]. Similar results with hydramethynon baits were reported for L. humile in Hawaii [9] and the lack of eradication was attributed to moldy bait, UV exposure and degradation of hydramthylnon, and the rapid speed of toxicity [9]. The difference in toxicant load between dead and live queens may also explain the resurgence of ants treated with hydramethylnon baits in the field. 
In our study queens were fed multiple times by workers, but some queens in the colony did not receive a lethal amount of hydramethylnon due to the social structure within a colony in which only one or two queens actively reproduce at one time. These queens received the bulk of the available nutrients, making use of their pheromone orchestration of colony behavior. Just $10 \%$ of queens were nutritionally dominant receiving up to 13 times as much as the other queens. Another $20 \%$ received about half the amount as the nutritionally dominant queens. The other $70 \%$ of the queens received very little nutrients at all from the workers within $96 \mathrm{~h} \mathrm{[29].}$ The "reserve" queens might attain lethal levels of toxicant only with long-term continuous exposure of the colony to hydramethylnon-based baits. However, the workers' dose is lower than the level required to kill all queens, and the trophic structure of the colony may not remain intact long enough to kill all queens. The lethal amount of hydramethylnon provided to queens through colony trophallaxis in this study $(10.9 \mathrm{pg})$ was much less than the lethal level of 88.5 pg previously found with direct feeding of $1.0 \mathrm{mg} / \mathrm{ml}$ solutions [23]. Hydramethylnon, a metabolic inhibitor, is most effective in the abdomen because of the high number of mitochondria present in the reproductive organs and the greater energy requirements of this process.

Our sampling of ants from the colony at the time of $50 \%$ lethality resulted in the recovery of live queens containing lethal amounts of fipronil. Apparently, the lethal dose of fipronil had not yet reached the thorax where the presence of numerous neuromuscular junctions and the nervous system would lead to lethal effects from the GABA antagonist. A mechanism appears to exist where storage can occur in the queen's head, perhaps through retention in the infrabuccal cavity that has previously been reported to act as a filter system for small particulates [31]. 
Fipronil is widely used as a spray because its delayed toxicity enables horizontal transfer from foraging ants $[32,33]$. Fipronil also shows promise as a potential bait toxicant for reducing populations of Argentine ants. Most of the queens in the laboratory colonies received very high levels of fipronil even though the initial bait concentrations were very low, indicating that the queens were fed multiple times. To enable numerous feedings of all queens, the colonies need to be exposed to low concentrations of fipronil and sucrose preparations for 3 to 5 days [34]. Aqueous sweet liquid baits are a promising way to introduce bait toxicants into colonies. A delivery system for liquid or gel [35] baits needs to be created that is economical and reduces evaporation so that the concentration of the toxicant remains constant and the solution does not become repellent.

\section{Acknowledgements}


We thank Elizabeth Bartko (University of California, Riverside) for assistance in rearing the ants. The technical and ${ }^{14} \mathrm{C}$-hydramethylnon were provided by The Clorox Services Co. The technical and ${ }^{14} \mathrm{C}$-fipronil was provided by Rhône Poulenc Ag. Co. This research was supported in part by a grant from the University of California Toxic Substances Research and Teaching Program, the UC Campus Laboratory Collaboration Program, The Clorox Services Co., and NIH NIGMS 8P41GM103483. This work was partially performed under the auspices of the U.S. Department of Energy by Lawrence Livermore National Laboratory under Contract DE-AC52-07NA27344. Paper reviewed and released as LLNL-JRNL-664517. The funders had no part in the design, implementation or data analyses. 


\section{References}

1. R.L. Knight and M.K. Rust, The urban ants of California with distribution notes of imported species, South. Entomol. 15(1990)167.

2. D.A. Holway, Competetive mechanisms underlying the displacement of native ants by the invasive Argentine ant. Ecology, 80 (1999) 238.

3. N. Roura-Pascual, A.V. Suarez C. Gomez, P Pons, Y. Touyama, A.L. Wild, and A.T. Peterson, Geographical potential of Argentine ants (Linepithema humile Mayr) in the face of global climate change, Proc. R. Soc. Lond. B, 271 (2004) 2527.

4. V. Vogel, J.S. Pederson, T. Giraud, M.J.B. Krieger, and L. Keller, The worldwide expansion of the Argentine Ant, Diversity Distrib., 16 (2010) 170.

5. M.W. Moffett, Supercolonies of billions in an invasive ant: What is a society? Behav. Ecol., 23 (2012) 925.

6. M.K. Rust and N. Su, Managing Social Insects of Urban Importance, Annu. Rev. Entomol. 57(2012)355.

7. K.G. Human and D.M. Gordon, Exploitation and interference competition between the invasive Argentine ant, Linepithema humile, and native ant species, Oecologia 105 (1996) 405.

8. F.R. Cole, A.C. Medeiros, L.L. Loope, and W.W. Zuehike. Effects of the Argentine ant on arthropod fauna of Hawaiian high-elevation shrubland. Ecology 73(1992)13131322.

9. P.D. Krushelnycky and N.J. Reimer, Efficacy of Maxforce bait for control of the Argentine ant (Hymenoptera: Formicidae) in Haleakala National park, Maui, Hawaii. J. Econ. Entomol. 27(1998) 1473. 
10. E.L. Vargo, L. Passera, Pheromonal and behavioral queen control over the production of gynes in the Argentine ant Iridomyrmex humilis (Mayr), Behav. Ecol. Sociobiol. 28(1991)161.

11. L. Keller, Evolutionary implication of polygyny in the Argentine ant, Iridomyrmex humilis (Mayr) (Hymenoptera: Formicidae): an experimental study, Animal Behavior 36(1988)159.

12. G.P. Markin, Food distribution within laboratory colonies of the Argentine ant, Iridomyrmex humilis (Mayr), Ins. Soc. 2(1970)127.

13. T. Eisner and E.O. Wilson, Radio-active tracer studies of food transmission in ants, Proc. 10th Internatl. Cong. Entomol. 2(1958) 509.

14. S.Y. Vega and M.K. Rust, Determining the foraging range and origin of resurgence after treatment of Argentine ant (Hymenoptera: Formicidae) in urban areas, J. Econ. Entomol. 96(2003) 844.

15. C.E. Stringer, Jr., C.S. Lofgren, and F.J. Bartlett. Imported fire ant toxic bait studies: evaluation of toxicants, J. Econ. Entomol. 57(1964) 941.

16. D.L. Cassill and W.R. Tschinkel. A duration constant for worker-to-larvae trophallaxis in fire ants, Ins. Soc. 43(1996)149.

17. J.G. Hollingshaus, Inhibition of mitochondrial electron transport by hydramethylnon: a new amidinohydrazone insecticide, Pest. Biochem. Physiol. $27(1987) 61$.

18. R.K. Vander Meer, D.F. Williams, and C.S. Lofgren, Degradation of the toxicant AC 217,300 in Amdro imported fire ant bait under field conditions, J. Agric. Food Chem. 30(1982) 1045. 
19. L.M. Cole, R.A. Nicholson, J.E. Cassida, Action of phenyl pyrazole insecticides at the GABA-gated chloride channel, Pestic. Biochem. Physiol. 46(1993)47.

20. C. Zhao, S.H. Hwang, B.A.Buchholz, T.S.Carpenter, F. Lightstone, J. Yang, B.D. Hammock, J.E. Casida. GABA receptor target of tetramethylenedisulfotetramine, PNAS 111 (2014) 8607.

21. A.D. Gunasekara, T. Truong, K.S. Goh, F. Spurlock, and R.S. Tjeerdema. 2007. Environmental fate and toxicology of fipronil, J. Pestic. Sci. 32(2007)189.

22. L.M. Hooper-Bui and M.K. Rust, Oral toxicity of abamectin, boric acid, fipronil, and hydramethylnon to laboratory colonies of Argentine ants (Hymenoptera: Formicidae), J Econ Entomol, 93 (2000)858.

23. L.M. Hooper-Bui and M.K. Rust, An oral bioassay for the toxicity of hydramethylnon to individual workers and queens of Argentine ants, Linepithema humile, Pest Manag Sci 57 (2001) 1011.

24. J.S. Vogel, Rapid production of graphite without contamination for biomedical AMS, Radiocarbon 34(1992)344.

25. B.A. Buchholz, S.P.H.T. Freeman, K.W. Haack, and J.S. Vogel, Tips and Traps in the Biological ${ }^{14}$ C AMS Prep Lab, Nucl. Instr. \& Meth, B 172 (2000) 404.

26. E. S. C. Kwok, B. A. Buchholz, J. S. Vogel, K. W. Turteltaub, and D. A. Eastmond. Dose-Dependent Binding of ortho-Phenylphenol to protein but not DNA in the Urinary Bladder of Male F344 Rats, Toxicol. Appl. Pharmacol. 159 (1999) 18.

27. M. Miyashita, J.M. Presley, B.A. Buchholz, K.S. Lam, Y.M. Lee, J.S. Vogel and B.D. Hammock. Attomole level protein sequencing by Edman degradation coupled with accelerator mass spectrometry, PNAS 98 (2001) 4403. 
28. G. Shan, W.Huang, S.J. Gee, B.A. Buchholz, J.S. Vogel and B.D. Hammock. Isotope Labelled Immunoassays without Radioactive Waste, PNAS 97 (2000) 2445.

29. Hooper, L.M. 1998. The nutritional ecology and effects of toxicants on colonies of Argentine ants, Linepithema humile (Mayr). Ph.D. Dissertation, University of California, Riverside. 157 pp.

30. L. M. Hooper, and M.K. Rust, Using bait to suppress the southern fire ant on an ecologically sensitive site (Hymenoptera: Formicidae), Sociobiology 31 (1998)283.

31. R. Eisner and G.M. Happ. The infrabuccal pocket of a formicine ant: a social filtration device, Psyche 69(1962)107.

32. D.H. Choe and M.K. Rust, Horizontal transfer of insecticides in laboratory colonies of the Argentine ant (Hymenoptera: Formicidae), J Econ Entomol 101 (2008)1397.

33. A.M. Soeprono and M.K. Rust, Effect of delayed toxicity of chemical barriers to control Argentine ants (Hymenoptera: Formicidae), J Econ Entomol, 97 (2004) 2021.

34. M.K. Rust, D.A. Reierson, and J.H. Klotz, Delayed toxicity as a critical factor in the efficacy of aqueous baits for controlling Argentine ants (Hymenoptera: Formicidae), J Econ Entomol, 97 (2004) 1017.

35. G. Buczkowski, E. Roper, and D. Chin, Polyacrylamide hydrogels: an effective tool for delivering liquid baits to pest ants (Hymenoptera: Formicidae), J. Econ. Entomol. 107 (2014) 748 . 


\section{Figure Captions}

Figure 1. Structures of (A) hydratmethylnon (tetrahydro-5,5-dimethyl-2-(1 H)pyrimidinone [3-[4-(trifluoromethyl)phenyl]-1-[2-[4-(trifluoromethyl)phenyl]ethenyl]-2propenylidene]hydrazone or AC 217, 300) and (B) fipronil (5-amino-1-[2,6-dichloro-4(trifluoromethyl)phenyl]-4-[(1R,S)-(trifluoromethyl)sulfinyl]-1H-pyrazol-3-carbonitrile).

Figure 2. The concentration of hydramethylnon in both live and dead members of an Argentine ant colony exposed to $1.0 \mathrm{mg} / \mathrm{ml}$ hydramethylnon suspended in an experimental sucrose liquid bait. Individuals were chosen from the colony at the time of 50\% lethality among each caste. The unfilled bars denote live ants and the filled bars denote dead ants at the time of sampling. The error bars are one standard deviation..

Figure 3. The concentration of fipronil in both live and dead members of an Argentine ant colony exposed to $0.1 \mu \mathrm{g} / \mathrm{ml}$ fipronil solution in an experimental sucrose liquid bait. Individuals were chosen from the colony at the time of $50 \%$ lethality among each caste. The unfilled bars denote live ants and the filled bars denote dead ants at the time of sampling. The error bars are one standard deviation. Despite receiving the same mass of fipronil, the live queens hold the toxicant in their heads, while the majority of fipronil was recovered in the thorax of dead queens. 
Figure 1

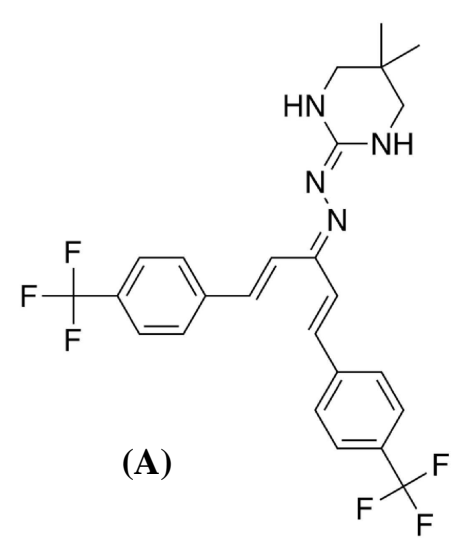

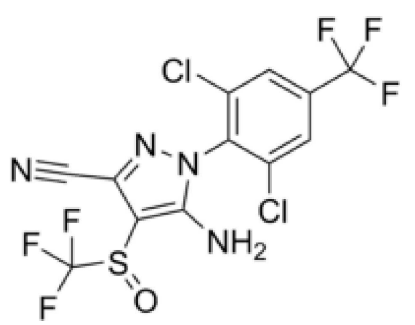

(B) 
Figure 2.

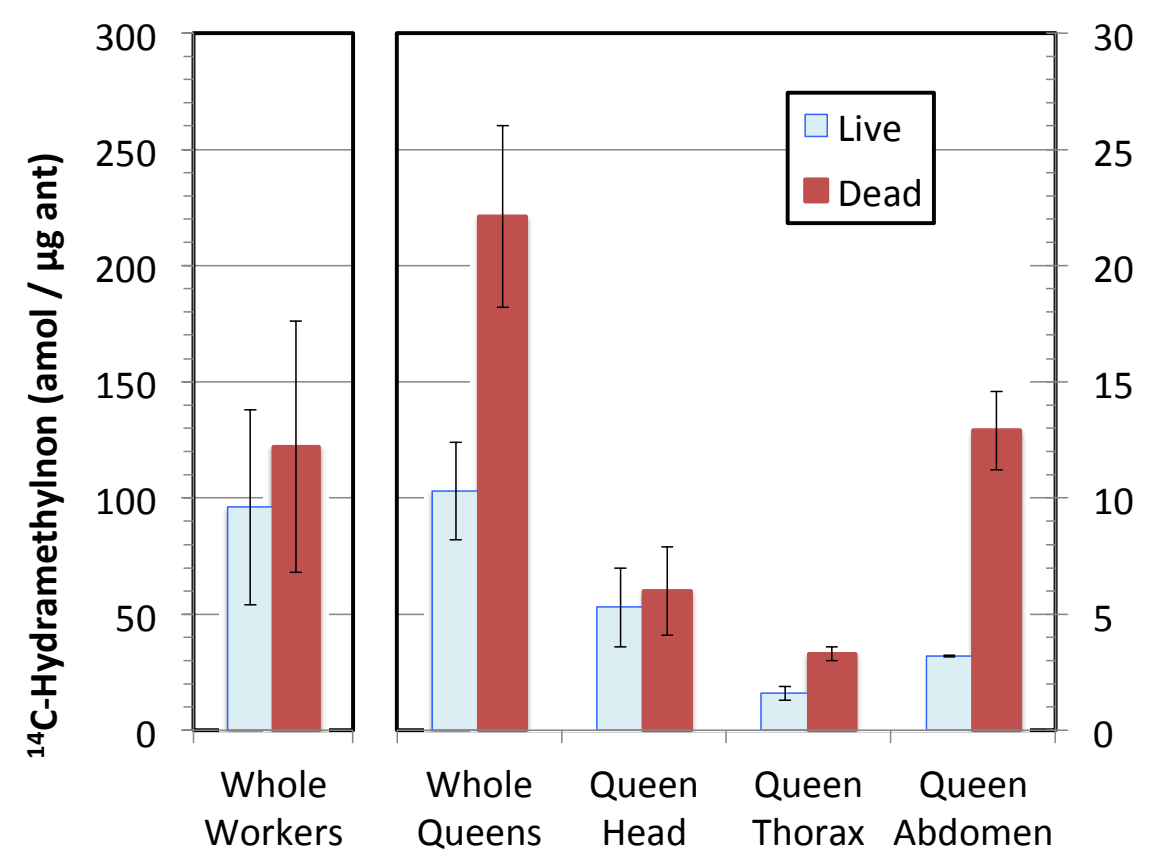

34

35

36

37

38

39

40

41

42

43

44

45

46

47

48

49

50

51

52

53

54

55

56

57

58

59

60

61

62

63

64

65 
Figure 3.

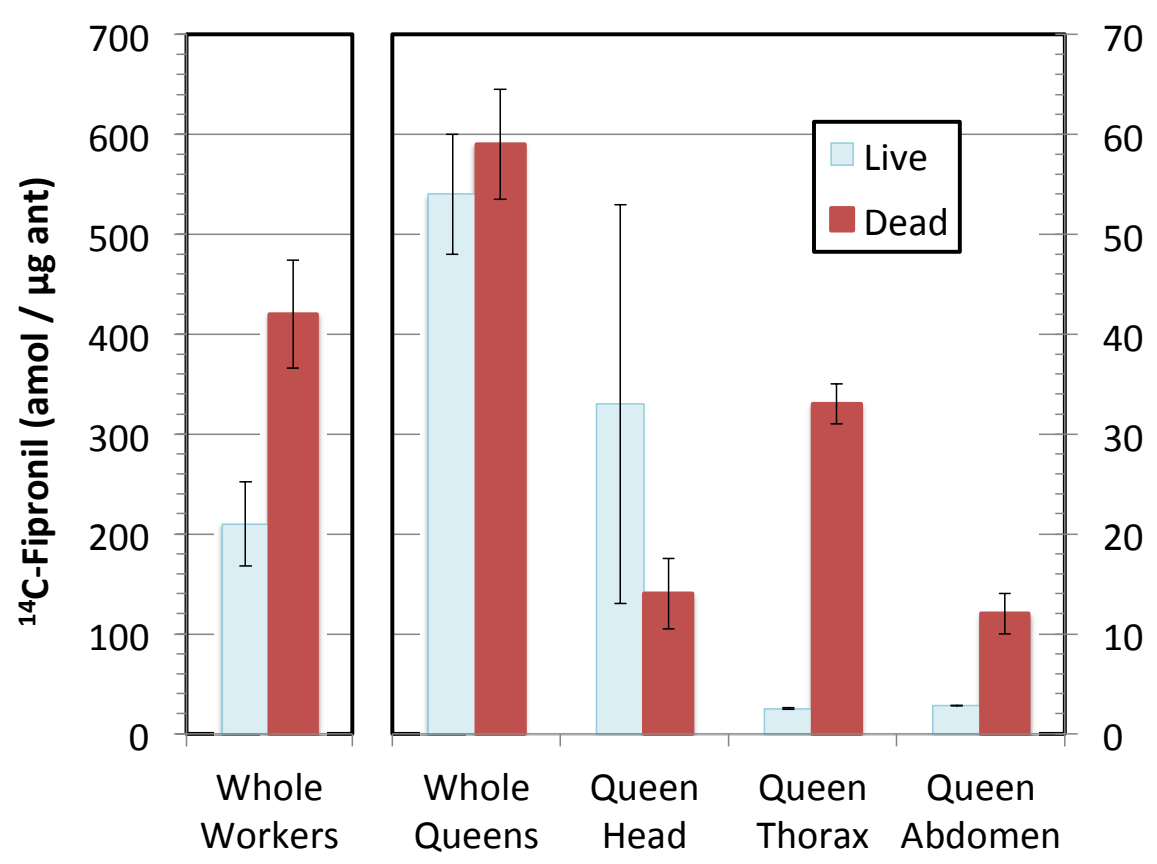

34

35

36

37

38

39

40

41

42

43

44

45

46

47

48

49

50

51

52

53

54

55

56

57

58

59

60

61

62

63

64

65 